\title{
Study of corrosion using long period fiber gratings coated with iron exposed to salty water
}

\author{
L. Coelho*a, J. L. Santos ${ }^{\mathrm{a}}$, P.A.S. Jorge ${ }^{\mathrm{a}, \mathrm{b}}$, J. M. M. de Almeida ${ }^{\mathrm{a}, \mathrm{c}}$ \\ ${ }^{a}$ CAP / INESC TEC - Technology and Science, Faculty of Sciences, University of Porto, \\ Rua do Campo Alegre, 687, Porto, Portugal \\ ${ }^{b}$ Department of Physics and Astronomy of Faculty of Sciences, University of Porto, \\ Rua do Campo Alegre, 687, Porto, Portugal \\ ${ }^{c}$ Department of Physics, School of Sciences and Technology, Universidade de Trás-os-Montes e \\ Alto Douro, Apartado 1013, 5001-801 Vila Real, Portugal
}

\begin{abstract}
A study of long period fiber gratings (LPFG) over coated with iron (Fe) and subjected to oxidation in water with different sodium chloride $(\mathrm{NaCl})$ concentrations is presented. The formation of iron oxides and hydroxides was monitored in real time by following the features of the LPFG attenuation band. Preliminary results show that Fe coated LPFGs can be used as sensors for early warning of corrosion in offshore and in coastal projects where metal structures made of iron alloys are in contact with sea or brackish water.
\end{abstract}

Keywords: Long period gratings, Fiber optic sensor; Oxidation of iron, Real time monitoring of corrosion

\section{INTRODUCTION}

The consequences of the corrosion of iron and its alloys have become a problem of worldwide significance [1]. Corrosion causes plant shutdowns, waste of resources, loss or contamination of products, reduction in efficiency, endanger safety and imposes expensive maintenance. The exploration of sea resources, such as deep sea mining and aquaculture, requires metallic structures, often made of iron alloys, which are exposed to corrosion [2]. In addition, activities such as dikes and the flooding of coastal marshland can produce brackish water pools for freshwater prawn farming. Brackish water is also the waste product of the salinity gradient power process [3]. In all these instances the control and monitoring of corrosion effects can be of critical importance.

Optical sensors based on long period fiber gratings (LPFGs) including, sensing of strain, bending, temperature, chemical analysis, vapor detection, food quality control and recognition of bacteria have been reported. A review on the fundamentals and on the main achievements obtained concerning LPFGs can be found in [4-6] and references therein. The physical properties of LPFGs rely on coupling light from the core mode of a single mode fiber into forward propagating cladding modes which translates in the appearance of attenuation bands in the transmission spectrum at specific wavelengths. The evanescent field of the cladding modes extends to the surrounding medium enabling refractive index measurements. Sensors based on LPFGs over coated with different metal oxides were fabricated and characterized for refractive index sensing. It was reported that oxidation of $\mathrm{Zn}, \mathrm{Ni}, \mathrm{Ti}, \mathrm{Al}$, and $\mathrm{Cr}$ into well-known oxide states can be monitored in real time by following the features of the LPFG attenuation band [7, 8]. LPFGs coated with metal oxides with specific properties leads to wavelength sensitivity enhancement when comparing to bare LPFG. In this work it is presented a preliminary study on the real time monitoring of iron thin films subjected to oxidation in water with different sodium chloride $(\mathrm{NaCl})$ concentrations using LPFGs in a temperature controlled environment.

*1coelho@inesporto.pt; phone +351 220402 301; $\underline{\text { www.inesctec.pt }}$ 


\section{MATERIAL AND METHODS}

LPFGs inscribed in single mode fiber (SMF28e, Corning, Inc.), were produced using the electric arc technique [4]. The period of the LPFG was $399 \mu \mathrm{m}$, a value chosen in order to obtain the assymetric $6^{\text {th }}$ order cladding mode resonance $\left(\mathrm{LP}_{1,6}\right)$ around $1.54 \mu \mathrm{m}$. A visibility value of $\sim 25 \mathrm{~dB}$ for the $\mathrm{LP}_{1,6}$ attenuation band of the bare LPFG was reached with a sensor length of $45 \pm 5 \mathrm{~mm}$. Depending on the oxidation process this attenuation band can shift down to around $1.51 \mu \mathrm{m}$.

A $40 \mathrm{~nm}$ thick film of Fe was produced around the grating region by thermal evaporation of pure metal (Goodfellow, U.K.) using an electron beam evaporator (Auto 306 from Edwards Ltd, U. K.) whose chamber was kept at $\sim 2 \times 10^{-6}$ mbar, fitted with a home-made rotary system in order to produce homogeneous coatings around the cylindrical fibers with a velocity of $\approx 5 \mathrm{rpm}$ [6]. A $2 \mathrm{~nm}$ layer of chromium was deposited to improve of the adhesion between the silica fiber and Fe thin film. A set of Fe thin films were deposited on silicon substrates for further SEM analysis of the surface morphology (SEM model QUANTA 400 FEG, FEI, USA).

The iron corrosion in salty water was simulated by adding $\mathrm{NaCl}$ (Sigma Aldrich, Germany) to pure water with a ratio of 1 and $3.5 \% \mathrm{w} / \mathrm{w}$. The coated fiber was clamped using a specially designed PTFE holder to keep the LPFG in position while avoiding bending. A bare LPFG was also added to the same holder in order to monitor the interaction of the silica with the $\mathrm{NaCl}$ solution at a constant temperature. The holder with the fibers was then submerged in the water solution in a polyethylene (PE) chamber previously heated to $40^{\circ} \mathrm{C}$ to minimize the time of temperature stabilization (Fig. 1). The complete system was then positioned in an sealed oven (IFA-32, Esco, Singapore) and kept at $40 \pm 0.3^{\circ} \mathrm{C}$ during the time of the experiment. The LPFG transmission spectra were recorded in real time using a FS2200 Braggmeter (FiberSensing SA, Portugal) working in the 1500 to $1600 \mathrm{~nm}$ range with $2 \mathrm{pm}$ of resolution. The procedure described was performed using pure water and solutions of 1 and $3.5 \%$ of $\mathrm{NaCl}$ with both bare and Fe coated LPFG.

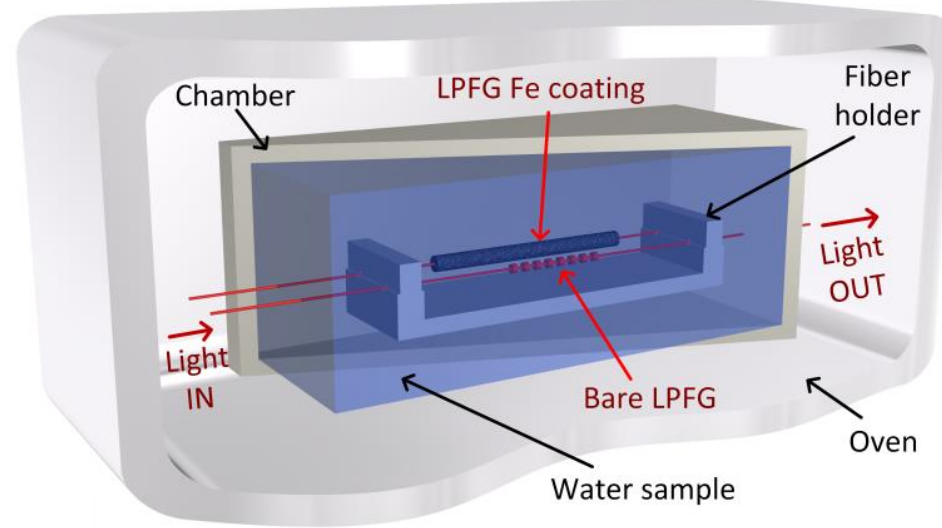

Figure 1. Experimental setup for study of $\mathrm{Fe}$ oxidation in $\mathrm{NaCl}$ water solutions constituted by a PTFE fiber holder and a polyethylene chamber placed inside an oven kept at $40^{\circ} \mathrm{C}$. The data acquisition unit in transmission mode is not shown.

\section{EXPERIMENTAL RESULTS AND DISCUSSION}

The transmission spectra shown in Fig. 2 corresponds to the $\mathrm{LP}_{1,6}$ mode of (a) bare LPFG and of (b) LPFG coated with $40 \mathrm{~nm}$ of $\mathrm{Fe}$ and immersed in a $3.5 \% \mathrm{w} / \mathrm{w}$ solution of $\mathrm{NaCl}$ at $40{ }^{\circ} \mathrm{C}$ up to 22 hours. Judging by the spectral characteristics of the bare LPFG, the experiment took place in isothermal conditions and the harsh solution seems to not affect the pure silica cladding. While the bare LPFG does not show either WLS or variation of the attenuation (optical power shift - OPS), the Fe coated LPFG presents a blue shift of about $19 \mathrm{~nm}$ and $\sim 5 \mathrm{~dB}$, respectively, for 22 hours at $40^{\circ} \mathrm{C}$.

The wavelength and the OPS behavior of the sensor with increasing $\mathrm{NaCl}$ concentration is presented in Fig. 3 . The bare LPFG does not present either WLS or variation of the OPS regardless the concentration of $\mathrm{NaCl}$. However, for the $40 \mathrm{~nm}$ Fe coated LPFG, the sensitivity of the WLS and of the OPS is higher for greater $\mathrm{NaCl}$ concentration. In fact, for this particular sensor, after $\sim 3$ hours exposure to the highest concentration the WLS response saturates at $\sim 16.5 \mathrm{~nm}$. 

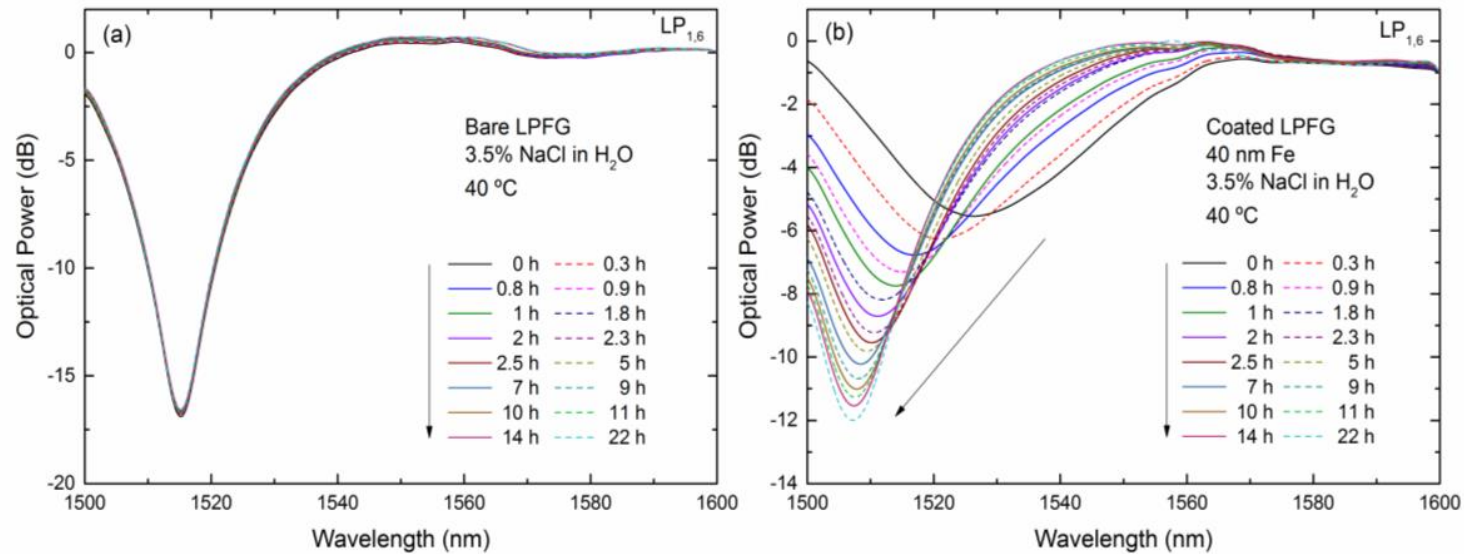

Figure 2. Transmission spectra corresponding to $\mathrm{LP}_{1,6}$ mode of a bare LPFG (a) and of a LPFG coated with $40 \mathrm{~nm}$ of Fe (b) and immersed in a $3.5 \% \mathrm{w} / \mathrm{w}$ solution of $\mathrm{NaCl}$ at $40^{\circ} \mathrm{C}$ up to 22 hours.

From the observation of Fig. 3 two outcomes can be highlighted: first, for this concentration an early warning sign of corrosion is set in less than 3 hours; and second, after this instant the sensor cannot be used in the WLS mode of operation but it may be used in the intensity mode up to $\sim 12$ hours. In addition, Fig. 4 illustrates the behavior of this type of sensors when exposed to $1.0 \% \mathrm{w} / \mathrm{w}$ solution of $\mathrm{NaCl}$ which can be found in places where mixing of seawater with fresh water occurs, as in estuaries or in brackish fossil aquifers [9]. A different behavior was observed, with a much slower WLS and OPS, due to the reduced $\mathrm{NaCl}$ concentration. For this concentration, the WLS of the sensor stabilizes after 21 hours and the OPS continues to diminish after 25 hours. The sensors immersed in pure water at $40^{\circ} \mathrm{C}$ and up to 25 hours showed no WLS. A slightly increase in the OPS (less than $0.5 \mathrm{~dB}$ ) can be seen in Fig. 4 (b), however this is within the experimental error. The silicon samples coated with $100 \mathrm{~nm}$ thick Fe films and subjected to the same conditions did not display any sign of oxidation when inspected with an optical microscope. As expected, air-free water has little effect upon iron metal [10].
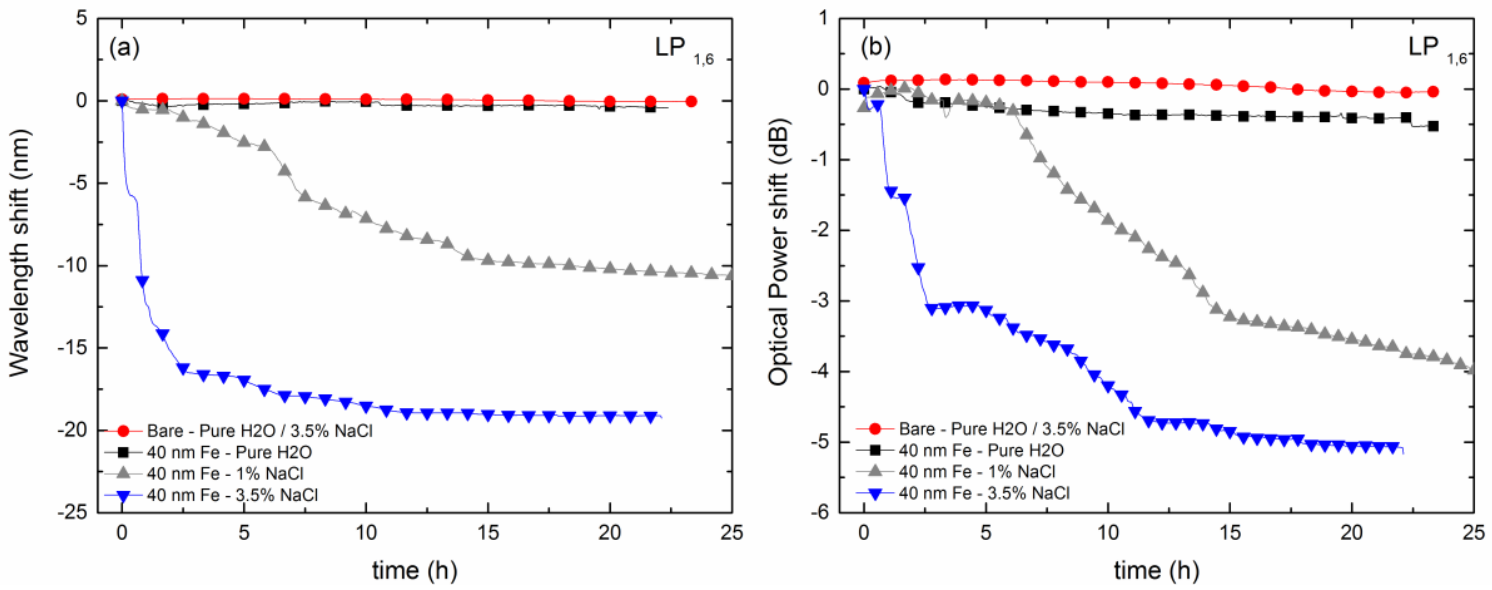

Figure 3. (a) Normalized WLS and (b) attenuation variation of the $\mathrm{LP}_{1,6}$ mode of a bare LPFG and of a $40 \mathrm{~nm}$ thick Fe coated LPFG immersed in pure water and in 1 and $3.5 \%$ w/w solution of $\mathrm{NaCl}$ at $40{ }^{\circ} \mathrm{C}$ up to 25 hours.

An analysis with SEM of the fiber gratings used in each experiment is presented in Fig. 4. The fibers coated with $40 \mathrm{~nm}$ of pure Fe metal (a) shows a very clean and homogeneous surface while after 20 hours immersed in $1 \% \mathrm{w} / \mathrm{w}$ (b) and $3.5 \% \mathrm{w} / \mathrm{w} \mathrm{NaCl}$ solutions at $40{ }^{\circ} \mathrm{C}$ (c), corresponding to already oxidized states the morphology changes completely. The latest picture, Fig. 4 (d), presents an identical fiber coated with iron after immersed in ultra pure water still showing a clean surface with low roughness, an indicator that pure water has little effect upon iron metal as was expected [10]. 

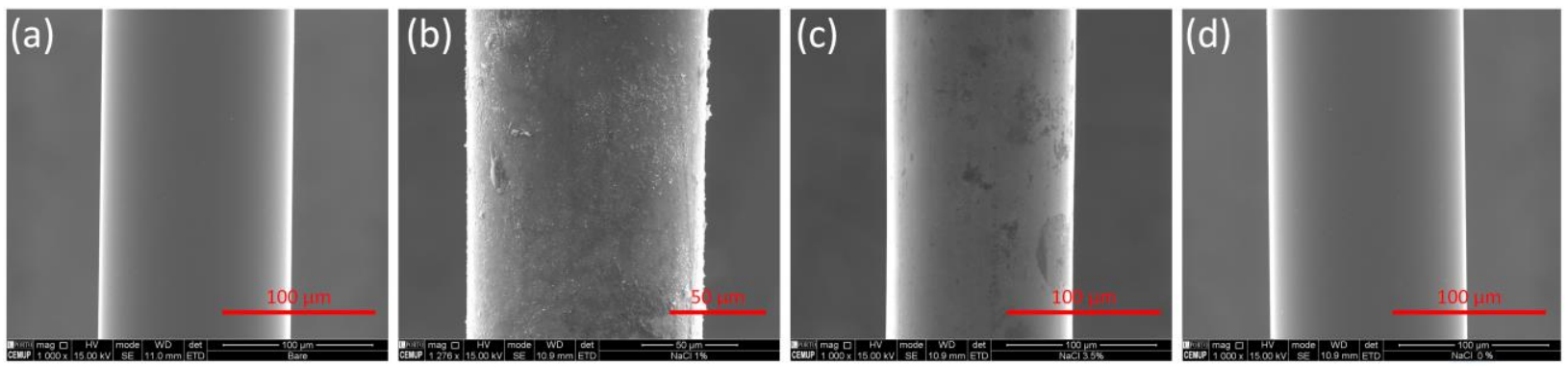

Figure 4. SEM photograph of optical fiber sensors coated coated with $40 \mathrm{~nm}$ of pure Fe as deposited (a), and immersed in $\mathrm{NaCl}$ solutions at $40{ }^{\circ} \mathrm{C}$; (b) $1 \% \mathrm{w} / \mathrm{w}$ after 25 hours; (c) $3.5 \% \mathrm{w} / \mathrm{w}$ after 22 hours; (d) and in pure water.

\section{CONCLUSIONS}

In this work real time monitoring of oxidation of iron thin films subjected to oxidation in water containing different sodium chloride $(\mathrm{NaCl})$ concentrations was studied for a set of experimental conditions using LPFGs. Preliminary results show that iron coated LPFGs can be used as sensors for early warning of corrosion of structures made of iron alloys. It also can be concluded that these kind of sensing devises are suitable to real time monitoring metallic structures in offshore deployments, where the $\mathrm{NaCl}$ concentration is around $3.5 \% \mathrm{w} / \mathrm{w}$, and in places where mixing of seawater with fresh water occurs, as in estuaries or in brackish fossil aquifers.

\section{ACKNOWLEDGEMENTS}

This work is financed by the "North Portugal Regional Operational Programme (NORTE 2020), under the PORTUGAL 2020 Partnership Agreement", and through the "European Regional Development Fund (ERDF)". within project Coral Sustainable Ocean Exploitation: Tools and Sensors/NORTE-01-0145-FEDER-000036."

\section{REFERENCES}

[1] H. Gräfen, E.-M. Horn, H. Schlecker et al., [Corrosion] Wiley-VCH Verlag GmbH \& Co. KGaA, (2000).

[2] R. Sharma, "Deep-Sea Impact Experiments and their Future Requirements," Marine Georesources \& Geotechnology, 23(4), 331-338 (2005).

[3] A. P. Straub, A. Deshmukh, and M. Elimelech, "Pressure-retarded osmosis for power generation from salinity gradients: is it viable?," Energy \& Environmental Science, 9(1), 31-48 (2016).

[4] G. Rego, J. Santos, and H. Salgado, "Refractive index measurement with long-period gratings arc-induced in pure-silica-core fibres," Optics Communications, 259(2), 598-602 (2006).

[5] I. D. Villar, I. R. Matías, F. J. Arregui et al., "Optimization of sensitivity in Long Period Fiber Gratings with overlay deposition," Optics Express, 13(1), 56-69 (2005).

[6] L. Coelho, D. Viegas, J. L. Santos et al., "Enhanced refractive index sensing characteristics of optical fibre long period grating coated with titanium dioxide thin films," Sensors and Actuators B: Chemical, 202, 929-934 (2014).

[7] L. Coelho, D. Viegas, J. L. Santos et al., [Real time monitoring oxidation of transition metals with long period fiber gratings], (2015).

[8] L. Coelho, J. L. Santos, D. Viegas et al., "Fabrication and Characterization of Metal Oxide-Coated Long-Period Fiber Gratings," Journal of Lightwave Technology, 34(10), 2533-2539 (2016).

[9] A. Moustakas, and I. Karakassis, "How Diverse is Aquatic Biodiversity Research?," Aquatic Ecology, 39(3), 367-375 (2005).

[10] N. Bertrand, C. Desgranges, D. Poquillon et al., "Iron Oxidation at Low Temperature $\left(260-500{ }^{\circ} \mathrm{C}\right)$ in Air and the Effect of Water Vapor," Oxidation of Metals, 73(1), 139-162 (2010). 